\title{
Una visión iusfilosófica de los principios del derecho y de los principios del derecho de familia
}

\section{POR RUBÉN MARCELO GARATE $\left(^{*}\right)$}

\begin{abstract}
Sumario: I. Sobre si el derecho es algo justo.- II. La fuente del derecho y los principios jurídicos.- III. La cuestión de los principios.- IV. Los principios en el derecho de familia.- V. Subrayando la importancia de los principios.- VI. La irrupción del derecho de fondo en el derecho adjetivo.- VII. A modo de conclusión.- VIII. Bibliografía.
\end{abstract}

Resumen: la filosofía jurídica siempre tiene algo que aportar al análisis del Derecho. Recientemente los principios jurídicos se han positivizado para lograr una mayor objetividad en la aplicación de las normas. Los principios sirven como criterios interpretativos dentro del sistema jurídico. Cuando la resolución judicial pretende tener cierto sentido de corrección, necesita encontrar una fundamentación racional basada en la tópica de los principios.

Palabras claves: principios jurídicos - argumentación - derecho de familia

\section{A iusphilosophical view of the principles of law and the principles offamily law}

Abstract: the legal philosophy always has something to contribute to the analysis of the Right. Recently, the legal principles have been positivitized in order to obtain greater objectivity in the application of the norms. The principles serve as interpretation criteria within the legal system. When judicial resolution pretends to have a certain sense of correction, it needs to find a rational foundation based on the principles' topic.

Keywords: legal principles - argumentation - family right

(*) Prof. en Filosofía y Ciencias de la Educación. Doctor en Derecho, Universidad Argentina John F. Kennedy. Esp. en Derecho de Familia. Prof. de Introducción al Derecho y Maestría de Sociología Jurídica, Facultad de Ciencias Jurídicas y Sociales, Universidad Nacional de La Plata, UNLP. 


\section{Sobre si el Derecho es algo justo}

En general cuando se piensa en la utilidad que nos pueden brindar las normas jurídicas, se suelen dar al menos dos repuestas. Algunos explican que las normas nos pueden proporcionar cierto grado de justicia, otros que sirven para asegurar la paz social. Dentro del primer grupo de pensadores encontramos a Aristóteles, quien dijo que las virtudes no surgen de una idealización conceptual, sino que se hacen realidad desde el obrar humano. Ellas suponen un hacer permanente, una conducta constante, una repetición de actos, que permitan la construcción, ni más ni menos que de un hábito. Así definía el filósofo griego la justicia, como un hábito de proporcionalidad, un justo medio entre el exceso y el defecto. Entre el exceso, por un lado, que nos lleva a la formalidad y rigurosidad y por el otro lado, el defecto que nos lleva a la falta de justicia o mejor dicho la injusticia. En el medio encontramos el punto medio de la equidad (Mondolfo, 1983, p. 295).

Cuando Aristóteles se pregunta sobre quienes son justos, responde que lo son quienes obedecen las leyes y observan las reglas de la igualdad. Es la legislación la que tiende a lo justo, puesto que las normas piden que nos comportemos de una forma virtuosa. Esto lo lleva a concluir que, si nos comportáramos de forma injusta, estaríamos dañando a otro (Aristóteles, 1999, p. 154). Le da a la justicia un sentido geométrico, en la medida que se pretenda evitar un mal mayor optando por un mal menor. Siempre es preferible el mal menor que la producción de un mal mayor.

Esto nos permite entender que hacer justicia, implica necesariamente elaborar preferencias, con base en la valoración de alternativas. Sin embargo, el filósofo nos dice que la justicia también tiene un sentido reparador. En estos casos, se considera que el reparto debe realizarse entre personas que son consideradas como iguales. Porque poseen los mismos derechos (sería el caso de los derechos humanos), porque ocupan un mismo rol (el caso de los trabajadores que pertenecen al mismo gremio) o teniendo distinto rol poseen iguales responsabilidades (como sucede con los padres). Para estos casos, hacer justicia implica reconstruir la desigualdad que provocó el daño sufrido por una de las partes.

En otra perspectiva están quienes entienden a la justicia como una mera posibilidad del orden social, afirmando que no es posible atender a todas las necesidades sociales, ni reparar por completo las desigualdades sociales. Sin embargo, el derecho puede asegurar la paz cuando el estado se asegura el monopolio de la fuerza, y solo la utiliza cuando se produce una transgresión. No se puede pensar el derecho sin esa característica esencial de ser un orden social coercitivo. En este sentido, resulta fundamental el rol del Estado, que pone en vigor el ordenamiento constitutivo de la sociedad. De ningún modo el derecho y la fuerza se excluyen entre sí, sino que existe entre ellos una relación profunda, en la medida que las 
normas autorizan el uso de la fuerza, con la única finalidad de mantener la paz social (Kelsen, 2003, p. 42).

Las constituciones, como norma fundamental del ordenamiento jurídico, tienden a asegurar y resguardar el derecho a la libertad de los miembros de la sociedad, pero esto solo sucede cuando se considera que cada individuo se siente obligado a su cumplimiento. De lo contrario, si nadie considera importante cumplir y exigir el cumplimiento de los derechos constitucionales, seguramente no se respetarían las libertades individuales, tanto por los otros miembros de la comunidad, como por parte de las distintas instituciones estatales.

Las normas se insertan en la realidad social, porque tienen una finalidad reguladora del comportamiento humano, esto se manifiesta en la función lógica que ellas tienen, que nos permite establecer las condiciones necesarias, para establecer el tipo de coacción de la conducta. Pero también se manifiesta en su función axiológica, en la medida que las normas permiten evaluar las acciones humanas como adecuadas o inadecuadas a los fines que ellas previeron. Esta caracterización nos permite reconocer distintos sentidos de las nomas, ya sea como derechoobligación o como derecho-pretensión. En el primer caso, referido a la realización de una acción u omisión, mientras que en el segundo caso como derecho-pretensión, referido a las distribuidoras de facultades jurídicas. En el primer grupo, encontraríamos a los derechos sociales reconocidos por la constitución y oponibles al Estado, mientras que en el segundo grupo encontramos a las garantías constitucionales. Bien podemos afirmar que la protección de la libertad y de los intereses individuales, es una posible razón para la existencia de los derechos-pretensión.

Las normas, como categoría trascendental del obrar humano se constituyen en un esquema de interpretación de las conductas, sobre la base del análisis lógico y axiológico, que ellas mismas proponen. En este sentido, como afirma Kelsen, los tribunales aplican normas jurídicas generales, cada vez que quieren dictar una sentencia, pero cada resolución judicial debemos considerarla como una norma individual, en tanto que establece una solución concreta, cada vez que determina una pena concreta o la ejecución civil que debe realizarse. Esto es así, porque el derecho se autorreproduce permanentemente, porque su aplicación provoca un proceso de individualización o concretización. Al juez no solo le compete verificar la producción del hecho antijurídico (quaestio facti), sino también determinar la norma general aplicable (quaestio iuris), para establecer en concreto las conductas que las partes deben desarrollar (Kelsen, 1991, p. 246). Este análisis se devela en el discurso jurídico, en la medida que las razones que fundamentan la sentencia, se expresan en los distintos argumentos, que se despliegan en una sucesión lógica de motivos. De modo tal que admita trazar una línea argumental que permita justificar la decisión tomada. Claro que en una sentencia pueden coexistir 
distintas líneas argumentales, pero esto solo en la medida que se pretenda analizar distintas cuestiones problemáticas, que puede presentar un caso específico, ya que se debe procurar la mayor coherencia argumentativa, procurando otorgar a la decisión judicial cierto grado de validez instrumental. Ello permite considerar a la resolución como el resultado más plausible en referencia a los argumentos esgrimidos (Pettoruti, 2004, p. 69).

Si tenemos en cuenta que Kant planteaba que en un sistema republicano de gobierno los derechos como así también las obligaciones tienen como base la igualdad de todos los ciudadanos. Bien podemos sostener que este principio, también fundamente el carácter instrumental de las normas jurídicas, por cuanto nos es permitido justificar su aplicación en razón de la búsqueda de una paz perdurable que le permita a cada hombre su desarrollo individual (Kant, 2007, p. 52). En definitiva, el derecho siempre se presenta como un medio para alcanzar fines sociales estimativamente superiores, como puede ser la paz o armonía familiar que garantizan y sirven de base, para el despliegue de las capacidades personales, en torno al grupo familiar que sirva de contención socioafectiva.

De una u otra forma, el derecho es un medio y no un fin en sí mismo, que nos permite asegurar el respeto a la libertad e igualdad de la persona humana, solo ella, puede ser considerada un fin valioso sobre el que se basa toda construcción social. Todos los esfuerzos que una sociedad realiza, no pueden tener mejor finalidad que procurar el logro de una convivencia que consolide el desarrollo individual de cada uno de sus integrantes. Por eso se dice que las comunidades que permiten un mejor nivel de vida, son relativamente más justas que aquellas que tienen situaciones de desigualdad, por lo que resulta necesario bregar por una mayor justicia social.

Cuando realizamos la pregunta ¿qué es hacer justicia para un operador jurídico? Entendemos, que pueden formularse distintas respuestas, muchas de ellas dependen de la perspectiva que se tenga del derecho. Es posible pensarla desde quien debe cumplir con las normas del derecho, estos son los que se sienten obligados y, por ello, nos muestran una faz externa, mientras que aquellos que deben aplicarlo, se encuentran obligados en forma directa a realizarlo, nos permiten reconocer una faz interna del derecho. La respuesta más sensata, desde una visión interna del derecho, que podrían elaborar los magistrados, funcionarios y abogados, responde a la necesidad de llevar a la práctica la concreción de las normas, bajo la fórmula de la razonabilidad de las resoluciones judiciales. En tanto productos de un discernimiento criterioso y prudente, en miras a lograr cierto grado de corrección y equidad en la solución del conflicto.

1) Las normas deben ser aplicadas, por lo cual, el tema de la eficacia siempre resulta ser una cuestión de fondo, sobre todo cuando se entiende que todos somos 
iguales ante la ley (artículo 16 de la Constitución Nacional) y, por lo tanto, no existen prerrogativas especiales en una comunidad democrática.

2) Cuando hablamos de normas, nos referimos a normas válidas tanto formal como materialmente.

3) La aplicación del derecho supone la exposición de un discurso razonable, que interprete la norma, establezca porque debe ser aplicada al caso y se formule respuesta concreta a la problemática jurídica que se pudiera haber planteado.

Sobre esta última cuestión pretendemos formular algunas líneas de reflexión, a fin de elaborar las características que deben reunir las decisiones razonada, y particularmente, establecer los elementos esenciales que deben ser tenidos en cuenta en una sentencia que se dicte dentro del ámbito del derecho de familia.

\section{La fuente del derecho y los principios jurídicos}

Uno de los temas más importantes dentro de la teoría general del derecho tiene que ver con las fuentes del derecho, ya que nos permiten establecer estos criterios objetivos sobre los que se debe determinar la juridicidad o antijuridicidad de las acciones. Siempre se ha dicho que el concepto de fuentes del derecho es un concepto multívoco, porque existen distintas definiciones de este concepto, aún dentro del campo jurídico, claro que dependen de la perspectiva y sentido que le queremos dar al término.

Kelsen, en su Teoría Pura del derecho, explica el proceso de derivación que se produce en el sistema normativo. Las normas de grada superior (normas generales), permiten a su vez la creación de normas particulares, estas últimas encuentran su fuente en las normas superiores, de las cuales decimos que se derivan en la medida que explicitan parte de su contenido. Al jurista le interesa reconocer cual es el derecho positivo, pero no todo el derecho, sino aquel que se encuentra vigente, aquellas normas que efectivamente son tenidas en cuenta por los distintos operadores jurídicos.

El Código Civil y Comercial comienza estableciendo, en su primer artículo, que todo caso debe resolverse teniendo en cuenta lo que dice la ley a la situación jurídica específica. Reconoce de esta forma el importante status que tiene la norma escrita, como fuente primaria, en nuestro ordenamiento jurídico, no obstante ello, a renglón seguido el artículo $1^{\circ}$ del Código determina que esta aplicación debe ser practicada conforme la Constitución y los tratados de derechos humanos, destacando así el carácter jerárquico que anima al sistema normativo, en el que se privilegia las reglas que tienen rango superior. De este modo, el legislador no ha querido señalar solamente una cuestión de importancia, sino también establecer que 
un juez no cae en el vacío cuando el ordenamiento jurídico no regula un caso particular, allí debe decidir utilizando aquellos fundamentos jurídicos que le aportan las normas de grado superior.

El artículo en análisis introduce la cuestión teleológica cuando dice que a efectos de su aplicación "se tendrá en cuenta la finalidad de la norma". El debate se genera cuando se excluyen los principios jurídicos del análisis y de la contextualización de la norma. Sin embargo, cuando los principios alcanzan su positivización pasando a formar parte del ordenamiento jurídico, al encontrarse formulados en la norma jurídica, quedan objetivados y con toda claridad, por lo que deben ser incluidos en la decisión judicial.

Entendemos que los principios jurídicos no determinan la resolución del caso, sino que solamente proporcionan razones que hablan a favor de la decisión. Ellos permiten construir una argumentación razonable, aportando criterios decisivos. No obstante, también le reconocemos a los principios una dimensión de peso, frente a situaciones de colisión entre distintas reglas. Los principios se diferencian esencialmente de las reglas en un sentido cualitativo, porque imponen su optimización en la mayor medida fáctica y jurídica posible. Debe interpretarse como un problema de optimización de derechos. Esto nos permite concluir que un juez, que aplica una regla, tiene que estar seguro que no infringe ningún derecho fundamental y que en su decisión optimiza la mayor cantidad de derechos. Esto provoca que reconozcamos a los principios como mandatos de optimización, en tanto que debe pretenderse su máxima realización.

Si afirmamos que el sistema jurídico no solo está compuesto por reglas de derecho, sino también por principios jurídicos, debemos tener en cuenta la necesidad de establecer una ponderación de los principios, a fin de valorar su contenido en referencia a la situación específica para la que debe ser aplicado. Dicha ponderación se debe traslucir en la sentencia judicial, si es que nos interesa hablar de corrección en el momento de tomar una decisión, en la medida que solo podemos establecer una justificación de esta última si ella nos refiere los principios que las sustentan.

La construcción del razonamiento judicial se apoya en una fundamentación lógica, cuya finalidad es provocar la legitimación del discurso jurídico. Así entendida, la sentencia resulta ser la comprensión lógica y axiológica de las normas, a fin de contextualizar la conducta humana normada (Cueto Rua, 1994, p. 126).

La actividad judicial implica no solo aplicar la norma, sino también la creación de una norma de grada inferior, en tanto que responde a una conflictiva específica, sobre la que se construye una norma particular plenamente ejecutable para cualquiera de las partes. Por eso, Vigo dice: 
Frente a esa visión jerárquica y confiada de la creación jurídica y la aplicación judicial ordinaria, nos parece que ya desde Kelsen se ha relativizado esa diferenciación y que una mirada realista y actual impone acordar que las diferencias entre esos dos momentos es más cuantitativa que cualitativa. En efecto, en la aplicación hay creación y viceversa, por lo que los distintos tipos de una y otra no pueden reconocerse a priori o a través del órgano sino sólo comprobando el resultado mismo, e incluso se ha señalado que la creación judicial significativa tiene que ver con el enunciado normativo general en el que efectivamente subsume el caso que resuelve y que garantiza la normatividad de la conclusión silogística (2009, p. 87).

\section{La cuestión de los principios}

En general se ha pensado a los principios jurídicos cuando por defecto de la ley no se encuentra norma alguna para su aplicación o cuando no existe costumbre sobre la cuestión en debate. Nunca se les ha negado un lugar en el ordenamiento jurídico, de hecho el Código de Vélez hacía referencia a ellos. Los principios claramente forman parte del derecho constitucional y los encontramos explicitados en el preámbulo. Se considera que son el resultado de una serie de abstracciones y de generalizaciones. Sin embargo, ellos tienen que ver con valoraciones normativas y criterios de valoración, sobre los que encuentra su fundamento el razonamiento jurídico.

Lo particular de los principios lo encontramos en su aspecto cognitivo, porque para que ellos pudieran ser efectivamente considerados, depende exclusivamente de su reconocimiento por parte de los tribunales, en especial considerando a las cortes como el último intérprete de la ley.

Existe una doctrina, de mediados del siglo XX, que se ha dado en llamar el principialismo, nacida de la reacción contra los regímenes autoritarios. Surgió a raíz de la desconfianza de los actos legislativos, sostiene que el derecho no es sólo la ley, sino algo más: los principios jurídicos. Algunos de ellos se encuentran redactados en la Declaración de los Derechos del Hombre y del Ciudadano de 1789, que pueden ser incluidos en los textos constitucionales, tal como sucede en el derecho argentino.

La ley no puede dejar de remitirnos a la Constitución, que a su vez nos reenvía, según el caso, a las Convenciones Internacionales. La solución de cualquier conflicto entre los distintos niveles normativos, debe ser resuelta por los jueces. De esta forma, los principios están sujetos a la interpretación de la norma. El artículo $1^{\circ}$ del Código establece que la interpretación "debe ser conforme con la Constitución Nacional y los tratados en los que la República Argentina sea parte". Teniendo en 
cuenta lo establecido en esta parte del artículo, podemos decir que, por un lado, la interpretación que realice el juez de las normas jurídicas debe ser integral, esto es, teniendo en cuenta a dicha norma como parte de un único ordenamiento, que se caracteriza esencialmente por su jerarquía normativa y su coherencia sistémica. Características que deben ser consideradas especialmente a la hora de dictar la sentencia, en la medida que la argumentación del fallo debe mostrar la unidad del sistema, la jerarquía constitucional de los tratados y convenciones, como así también la coherencia en la aplicación de las de las normas específicas, con la normativa convencional. Solo de esta forma los argumentos jurídicos utilizados en la sentencia pueden lograr cierta racionalidad, por más que los principios se encuentren sujetos a la interpretación de los jueces.

La intención del órgano jurisdiccional no puede ser otra que alcanzar cierto grado de corrección en la decisión. Para lograr esto, los caminos procedimentales deben tender a conjugar las normas en juego, las conductas que han generado el conflicto y resultan ser el objeto del análisis jurídico, y las valoraciones que podemos hacer sobre estas conductas, en función de aquello que las propias normas nos refieren. No se puede dejar de tener en cuenta que toda decisión jurídica conlleva un sentido axiológico (Herrera Figueroa, 1955, p. 133). Este tipo de decisiones requieren un discurso práctico, deben utilizar en su proceso de construcción aquellos principios jurídicos consagrados por el derecho positivo, que le permitan aportar mayor racionalidad a la sentencia (Alexy, 2008, p. 136).

El Código estipula una serie de normas tendientes a hacer efectivos los derechos subjetivos, estableciendo directivas procesales. Esta situación encuentra su fundamento en las garantías constitucionales, que de conformidad con el artículo 31, resultan encontrarse ampliadas a los tratados internacionales, por ser considerados ley suprema de la nación. Es el mismo Código que posibilita una interpretación jurídica amplia, en el cual las reglas, los principios y los valores no están ajenos, ya que la norma constitucional y las convenciones internacionales señalan expresas directivas sobre la función del Estado.

Los principios jurídicos bien pueden ser vistos como directivas o criterios racionales, en la medida que permiten el ejercicio de una interpretación dinámica de las normas generales.

Cuando hoy se habla de un control constitucional se hace referencia al resguardo de los derechos y garantías constitucionales. Bien podemos destacar, una vez más, que estos derechos han quedado amplificados por el artículo 75 inc. 22 de la Constitución Nacional a los tratados ratificados por la Nación. De esta forma, también se infiere la existencia de un control convencional de las decisiones judiciales y la importancia e influencia de las decisiones de los organismos internacionales de control. Todo ello, en función de lograr una tutela eficiente de los derechos. Por 
ello, se puede comprender que resulten tan relevantes las situaciones de vulnerabilidad que puedan producirse, porque ellas requieren una respuesta urgente de los órganos administrativos y judiciales.

\section{Los principios en el derecho de familia}

El Código Civil y Comercial, a partir del artículo 706, establece principios procesales que orientan y direccionan la actividad jurisdiccional. Lo interesante es que estas directivas procesales fueron formuladas para lograr una satisfacción plena de los derechos. Si bien, esta intromisión ha recibido distintas críticas por la intromisión del legislador nacional en las cuestiones procesales, que no fueron expresamente delegadas constitucionalmente por las Provincias, evidentemente la intención del codificador ha sido la de brindar criterios procedimentales comunes, para establecer herramientas generales que permitan la efectividad del derecho sustantivo.

En este caso, bien cabe reconocer dos cuestiones importantes. La primera tiene que ver con entender que el derecho no está conformado por compartimientos estancos e independientes, como bien fuera considerado por Hans Kelsen, al considerar que el derecho es único y por eso hablamos de un ordenamiento jurídico y no de un conjunto de normas yuxtapuestas. Es más, cuando formula la disolución del dualismo entre el derecho público y el derecho privado, señala que esta diferenciación es solo metodológica, en razón del órgano que las crea y no en razón de su validez.

Por otro lado, debemos considerar que estos principios que enuncia el Código Civil y Comercial no son contradictorios con el resto de las normas del sistema jurídico, sino todo lo contrario, son por demás favorables a la efectividad de las reglas generales, porque han sido formulados bajo un criterio de coherencia normativa.

Debemos destacar que estos principios colocan el acento en el rol del juez, porque sobre él se pone la obligación de hacer cumplir las cargas procesales. El juez pasa a ser un actor importante en los conflictos de familia, limitando de esta forma el principio dispositivo.

Los nuevos paradigmas convencionales obligan a favorecer el bienestar familiar y asegurar el interés superior del niño a fin de garantizar sus derechos. Esta finalidad se puede logar cuando se garantiza el principio de inmediatez. El juez tiene en sus manos la responsabilidad de obtener el conocimiento directo de quienes intervengan en el conflicto, su historia personal, su situación particular, y todo otro dato que le permita configura la toma de medidas estratégicas de contención. El protagonismo judicial se exterioriza no sólo en la escucha directa del 
niño, con el debido respeto a sus "tiempos", sino, además, en la conducción directa del caso. Un signo eficiente de la contención debe estar reflejado en el trabajo interdisciplinario, que en el derecho de familia no es una novedad sino una necesidad, para lograr una comprensión necesaria de las relaciones familiares desde una perspectiva integral que permita intervenir con equilibrio y apuntalar lo que sea estrictamente necesario, intervención que debe estar conducido y orientado por quién deberá tomar la decisión final.

La tutela judicial efectiva tiene que ver con la preocupación por lograr la real aplicación de los derechos. Se relaciona con el paso de la teoría a la praxis. En definitiva, con esa concreción de los derechos, aquello de lo cual nos hablan las convenciones (artículos 8 y 25 Convención Americana de Derechos Humanos). Este principio se relaciona con el derecho de acceso a la justicia, que implica una rápida acción de la justicia ante un reclamo, un pronto trámite, el dictado de una sentencia efectiva, y la satisfacción sobre el servicio de justicia.

Ahora bien, la tutela judicial diferenciada, con relación a las cuestiones de familia, exige reglas propias y flexibles, en especial por la urgencia de algunas cuestiones, como la problemática de la violencia familiar y de género.

Este principio requiere un proceso en el cual el juez desarrolle un rol activo, en el que las partes acerquen pruebas conducentes en el marco de un procedimiento flexible que posibilite las soluciones autocompuestas, y que los espacios de diálogo produzcan los acuerdos necesarios para lograr la continuidad de las obligaciones familiares, siempre parciales, frecuentemente revisables, posibles y realizables.

La inmediación responde a este principio, el contacto directo y personal del juez con el justiciable. Esto tiene como finalidad asegurar el real conocimiento, por parte del magistrado, de la conflictiva sobre la que debe pronunciarse. La presencia del juez en la audiencia es la forma en la que el Código pretende asegurar el contacto directo con las personas involucradas, para asegurar la inmediación.

La buena fe responde a un aspecto ético de las conductas que se despliegan durante el proceso. Dicho sea de paso, por más que tenga que ver con la forma de comportarse, son conductas exigibles, porque hacen a la cooperación en el desarrollo del proceso y a buscar el interés familiar como norte de la actuación jurisdiccional.

Esta conducta debe ser evaluada según el desempeño en la actividad procesal, ya que lo contrario tiene que ver con el ejercicio abusivo de los derechos, provocando dilaciones innecesarias y manteniendo una postura intransigente que impide cualquier tipo de acuerdo, con la sola intención de imponer su voluntad, 
o evitando todo tipo de cooperación que facilite la concreta evaluación de la problemática.

La oficiosidad tiene que ver con la capacidad del juez de intervenir activamente en el proceso, no solo como aquel que debe dictar una sentencia, sino a quien le corresponde buscar la verdad real e instar la producción de los distintos pasos, a fin de resolver las cuestiones que requieran pronunciamientos urgentes.

La oralidad responde a este principio que, seguramente, con el tiempo y siguiendo el trámite de las distintas propuestas de modificación del Código Procesal, tienda a modificarse hasta alcanzar un proceso por audiencias, tendiente a encontrar una forma más expeditiva, en miras a lograr una solución del conflicto y una mayor agilidad en las cuestiones probatorias que disminuya el retraso de las sentencias.

El acceso limitado al expediente se vincula con el resguardo de los derechos a la dignidad e identidad de las personas. Se pretende con ello resguardar a las partes, preservando en la intimidad las cuestiones tan personales que se relacionan con los vínculos familiares, cuya divulgación puede provocar ciertos perjuicios a los interesados. También la reserva de las actuaciones se relaciona directamente con el secreto profesional, en la medida que las cuestiones de la esfera privada familiar son ventiladas ante los operadores jurídicos con la única finalidad de obtener un pronunciamiento jurisdiccional.

La resolución pacífica de los conflictos se relaciona con la inmediación en materia procesal y con la posibilidad de encontrar soluciones producto de la autocomposición. Los operadores jurídicos tienen la facultad de peticionar y/o celebrar audiencias conciliatorias en todas las distintas etapas del proceso, siempre que sean razonables y pertinentes.

Especialización y trabajo multidisciplinario: los temas jurídicos deben ser abordados por los profesionales del derecho, pero en materia de familia bien podemos decir que el derecho no alcanza, se necesita una aproximación multidisciplinar, con la ayuda de especialistas en distintos campos de las ciencias sociales.

La especialización en materia de familia se refiere, por un lado, al conocimiento de la problemática y, por el otro, a un trabajo sectorizado en el área de los temas de familia, que debe ser manejada por operadores altamente calificados, capaces de reflexionar, considerar y aplicar los cambios que puedan darse en materia convencional, con motivo de las sentencias de los tribunales superiores o de los consejos por parte de los organismos de seguimiento. Los temas jurídicos deben ser abordados por los profesionales del derecho, especializados en el derecho de familia. 


\section{Subrayando la importancia de los principios}

Cuando se habla de principios parece que se hace referencia a cuestiones abstractas que no tienen que ver con la realidad del derecho sino con aspectos puramente teóricos. Si bien no podemos dejar de reconocer que los principios se relacionan con los aspectos de la teoría general del derecho, ellos tienen una vinculación directa con lo ideológico, simplemente porque marcan un camino que debe ser tenido en cuenta.

Los principios tienen una proyección sobre todo el derecho porque establecen, en definitiva, el modo en que debe ser interpretado el derecho y cómo se debe aplicar. Esto nos permite vislumbrar la importancia que la teoría tiene que ver con la práctica, como así también la relación entre los principios y lo que esperamos del derecho. Si tenemos un sistema jurídico es porque consideramos que nos puede servir para algo, por lo tanto, es lógico que nos interese que este sea eficaz.

Los principios jurídicos no solo tienen que ver con la validez normativa, sino también con la eficacia. En definitiva, lo que queremos decir es que los principios juegan un rol importante en la actividad de los operadores jurídicos, por más que no tengan tanta visibilidad. Particularmente, los principios procesales guían el desarrollo del proceso, pero también el fallo de los jueces.

Los principios tienen que ver con valoraciones que hacemos sobre el derecho, como puede ser el que surge del reconocimiento sobre la libertad personal, enunciado en el artículo 14 de la Constitución Nacional y garantizado por los artículos 18 y 19 del mismo texto normativo, pero también los principios pueden ser utilizados como criterios de interpretación y análisis de las normas.

Los principios vienen a traer mayor flexibilidad a la aplicación de las normas. Recordemos, en este sentido, que la escuela de la exégesis tenía en cuenta que para interpretar la ley había que tener en cuenta que tan compleja era. Así, si la ley era clara bastaba con sostener dura lex sed lex - la ley es dura pero es la ley-y, por lo tanto, debe ser aplicada, mientras que si presentaba alguna dificultad había que buscar la ratio legis, esto implicaba tratar de entender los motivos que llevaron al legislador a sancionar dicha ley, por lo que el jurista debía considerar las notas aclaratorias del codificador. Pero cuando el texto era totalmente oscuro, debía recurrir a los principios del derecho y a la analogía jurídica.

No obstante ello, los principios, cuando se encuentran formulados específicamente por la propia norma, no solo permiten la interpretación de las normas de las que pueda resultar, en su redacción, cierta oscuridad, sino toda vez que una norma - en este caso del derecho de familia - deba ser aplicada. Y, más aún, son los principios los que permiten completar las lagunas jurídicas, esos vacíos 
normativos que se pueden presentar cada vez que una situación conflictiva no tiene una respuesta directa en el texto de la ley.

Los principios procesales son directrices que establecen una orientación, la actividad creadora del juez; en tanto que reconocemos a la sentencia como una norma particular formalmente válida. Brindan, además, pautas generales que deben guiar la decisión de los jueces.

En este caso, los principios enunciados en el artículo 706 y siguientes son de naturaleza procesal en la medida que permiten la mayor efectividad y provocan un pronunciamiento jurisdiccional acorde a los derechos constitucionales y convencionales.

Los principios en el ámbito del proceso, como sucede en el caso del artículo 706 del Código Civil y Comercial, le dan a las reglas adjetivas procesales su orientación y establecen finalidades del sistema procesal, indicando aquello que debe ser tenido en cuenta, ya sea durante el proceso o, a la hora de dictar la sentencia. Si bien podemos reconocer en las normas procesales una estructura deóntica que las asemeja a las reglas técnicas, los principios procesales por su sentido imperativo presentan un carácter netamente prescriptivo, ya que limitan la conducta de los distintos operadores jurídicos, a la hora de pensar, decir y aplicar el derecho.

El artículo 706 establece los principios que deben ser respetados en el proceso en materia de familia. En resumen, expresa como se deben tutelar los derechos, será por eso que comienza hablando de la tutela judicial efectiva, que se hace concreta en la escucha, por parte del órgano jurisdiccional, de los conflictos que provocan una violación o un perjuicio a los derechos.

La tutela judicial efectiva nos habla del tipo de intervención judicial, esto es en el marco de un proceso en el que las partes puedan demandar, probar y defenderse; ello tiene que ver eminentemente con el derecho de acceso a la justicia y con la efectiva intervención judicial cada vez que se denuncie una vulneración de aquellos derechos, sobre los cuales se pretenda una reparación.

Este aspecto tiene su correlato en el artículo 10 de la Convención Universal de Derechos Humanos, que afirma que toda persona tiene derecho a ser oída públicamente y con justicia por un tribunal independiente e imparcial, a fin de determinar sus derechos y obligaciones.

La Convención Americana de Derechos Humanos nos dice en su artículo 8 que las garantías judiciales tienen que ver con el derecho de toda persona a ser oída, en un plazo razonable, por un juez o tribunal competente, independiente e 
imparcial, establecido con anterioridad por la ley; esto también implica garantizar el derecho de defensa y el derecho de recurrir ante un tribunal superior.

En el mismo sentido, la Convención, en su artículo 25, complementa su interpretación al referirse a la protección judicial, garantizando el derecho a un proceso sencillo, rápido y efectivo ante un juez competente, que ampare contra aquellos actos que violen sus derechos fundamentales cuando sean cometidos por personas que actúen en ejercicio de sus funciones.

La normativa precitada se circunscribe en el consolidación del principio pro actione, que establece que el intérprete ha de seleccionar y aplicar la norma que en cada caso resulte más favorable para la persona, para asegurar su libertad y sus derechos. Se trata de un criterio hermenéutico que informa todo el derecho de los derechos humanos, en virtud del cual se debe acudir a la norma más amplia, o interpretación más extensiva, cuando se trate de reconocer derechos protegidos e, inversamente, a la norma o a la interpretación más restringida cuando se trata de establecer restricciones permanentes al ejercicio de los derechos o su suspensión extraordinaria (Bidart Campos, 2000, p. 391).

Los principios procesales se conforman como directivas del ordenamiento jurídico procesal. Si bien estos se encuentran sujetos a los cambios interpretativos, en virtud de los paradigmas que influyen en las ciencias jurídicas, en la actualidad existe un positivo incremento de facultades y deberes que posicionan al juez en un rol distintivo que lo pone como un factor activo del proceso, dándole una función de conducción.

Para asegurar la tutela judicial efectiva hay que tener en cuenta que el cumplimiento de una resolución judicial debe verse precedida de una serie de pautas. En consecuencia, la decisión judicial que dirima una situación legal implica el agotamiento de las instancias recursivas o las vías que el derecho proporcione para su cuestionamiento o aceptación. Pero esta resolución no puede ser postergada o ser dilatada en el tiempo. Sin embargo, la tutela judicial que se encuentra en profunda relación con el derecho de acceso a la justicia, depende de la real disposición de mecanismos e instrumentos de ejecución, que generen una concreta operatividad de los fallos judiciales, algo por lo cual los jueces y distintos operadores deben trabajar.

La tutela judicial efectiva se viabiliza como derecho a ocurrir ante los tribunales y obtener una sentencia útil, acceder a una instancia judicial ordinaria para lograr el control judicial suficiente, accediendo a un juez natural e imparcial. Esto implica acceder a la jurisdicción, asegurar el derecho a ser oído, a ofrecer y producir prueba, a una decisión fundada, a recurrir la ejecución oportuna de la sentencia luego del desarrollo de un proceso producido en un plazo razonable. La efectividad de la tutela depende de la aplicación diaria de los órganos jurisdiccionales, 
produciendo resultados útiles, concretos y perceptibles, que afecten la vida de los ciudadanos y satisfaga las legítimas expectativas de las partes.

El artículo 26 del Código Civil y Comercial (CCiv. y Com.) establece, con relación a las personas menores de edad, que "(...) tiene derecho a ser oída en todo proceso judicial que le concierne así como a participar en las decisiones sobre su persona (...)". No obstante, las personas a las que se les debe limitar sus capacidades deben ser entrevistadas por el juez, como lo establece el artículo 35 del CCiv. y Com. "(...) asegurando la accesibilidad y los ajustes razonables del procedimiento de acuerdo con la situación de aquél (...)". Para el descernimiento de la tutela y toda otra decisión en la que se encuentre afectado un menor de edad, el juez debe oír, tener en cuenta sus manifestaciones, y a la hora de decidir tener en consideración el interés superior del niño, niña o adolescente (artículo 113 CCiv. y Com.). Obligación que tiene su proyección ante la falta de edad nupcial, menor de 16 años, situación en la que el juez debe mantener una entrevista con los contrayentes y los representantes legales, a fin de evaluar la opinión de estos últimos y la madurez de los menores (artículo 404 CCiv. y Com.). También la audiencia en el proceso de divorcio para evaluar las propuestas reguladoras realizadas por las partes, como lo establece el artículo 438 del CCiv. y Com. En el caso de la adopción, el juez debe garantizar el derecho del niño a ser oído y que su opinión sea tenida en cuenta según su edad y grado de madurez, siendo obligatorio requerir su consentimiento a partir de los diez años (artículo 595 CCiv. y Com.). Una de las reglas del procedimiento de adopción es la obligatoriedad de la entrevista personal del juez con los padres (artículo 609 CCiv. y Com.). Asimismo, el juez debe oír personalmente al pretenso adoptado y tener en cuenta su opinión (artículo 617 CCiv. y Com.); como así también con relación al apellido del pretenso adoptante (artículo 626 CCiv. y Com.). En el caso de la adopción de integración, las reglas establecen que los progenitores de origen deben ser escuchados (artículo 632 CCiv. y Com.). En el caso de los temas referidos a la responsabilidad parental, el derecho del niño a ser oído (artículo 639 CCiv. y Com.). Con relación a la delegación de la responsabilidad parental, el artículo 643 del CCiv. y Com. establece que los acuerdos al que lleguen los progenitores con la persona que acepta la delegación deben ser homologados judicialmente, debiendo oírse necesariamente al hijo. Estos son válidos por 1 año, pudiendo renovarse judicialmente por razones debidamente fundadas, por un período más con participación de las partes involucradas. Pero también, en el caso con el hijo adolescente (artículo 678 del CCiv. y Com.) establece en el caso que quiera iniciar una acción civil contra un tercero, el juez puede autorizarlo a intervenir en el proceso con la debida asistencia letrada, previa audiencia del oponente y del Ministerio Público.

No obstante, el codificador ha subrayado con expresa claridad que uno de los principios procesales tiene que ver con la inmediación y la oralidad, así en el 
artículo 707 del CCiv. y Com. Esto particularmente tiene que ver con la participación en los procesos de familia, en los que se encuentran involucradas tanto las personas con capacidad restringida como los niños, niñas y adolescentes. Se les reconoce el derecho a ser oídos en todos los procesos que los afecten de forma directa, opinión que debe ser valorada y tenida en cuenta según su grado de discernimiento y las particularidades que pueda presentar la cuestión debatida en el proceso.

Bien podemos reconocer que este artículo tiene como base lo establecido en la Convención sobre los Derechos del Niño, cuando en el artículo 9.2 se dispone que "En cualquier procedimiento entablado de conformidad con el párrafo 1 del presente artículo, se ofrecerá a todas las partes interesadas la oportunidad de participar en él y de dar a conocer sus opiniones", como así también en el artículo 13 de la Convención de las Personas con Discapacidad, que obliga a los Estados parte a asegurar que las personas con discapacidad tengan acceso a la justicia en igualdad de condiciones con las demás, incluso mediante ajustes de procedimiento y adecuados a la edad, para facilitar el desempeño de las funciones efectivas de esas personas como participantes directos e indirectos, incluida la declaración como testigos, en todos los procedimientos judiciales, con inclusión de la etapa de investigación y otras etapas preliminares.

En este caso, si bien podemos decir que el Código Civil y Comercial introduce temas del derecho procesal, incluyendo normas del derecho adjetivo, lo hace con la intención de responder a los estándares establecidos por las convenciones internacionales en los que la Nación es parte.

Plantear la inmediación como una práctica general en los procesos de familia, guarda relación con otorgarle al juez herramientas que le permitan enriquecer su percepción de la problemática familiar. La realidad familiar se empobrece si esta queda atada a una visión formalista donde no se pueden percibir los vínculos reales que dan vida a cada relación familiar.

En la actualidad, el Código Civil y Comercial de la Nación adopta una posición filosófica moderna, al implementar un método práctico-prudencial, que implica reconocer que el derecho no se encuentra solo en la ley y limitado por ella, sino también que se reconoce la importancia de las otras fuentes del derecho y su operatividad en la creación del Derecho. El sistema jurídico supone reglas, principios y valores, que encuentran su fundamento en el paradigma del Estado de Derecho Constitucional.

Esta nueva perspectiva nos permite entender por qué el Código le asigna al juez un rol distintivo cuando el derecho debe ser interpretado y aplicado. La única forma de garantizar la operatividad de esta visión del derecho depende de la 
enunciación de principios y reglas procesales que garanticen una aplicación eficiente, esto implica favorecer un modelo de juez proactivo, dejando de lado el modelo de juez árbitro.

\section{La irrupción del derecho de fondo en el derecho adjetivo}

Uno de los principios más importantes, que tiene una repercusión directa en materia procesal, es la tutela judicial efectiva, que muestra a las claras el nuevo rol que se le asigna al juez, quien debe asegurar el derecho a la prestación de una justicia efectiva. Esto nos permite entender que el derecho privado que responde a intereses individuales, de alguna manera encuentra una correlación de intereses con el derecho público en el resguardo de los intereses de los más vulnerables.

La función pública del proceso, que consiste en asegurar la operatividad del derecho, encuentra sustento en el proceso de constitucionalización del derecho procesal, que sustenta la superioridad de la Constitución sobre la ley. La incorporación de la garantía de la tutela judicial efectiva, consagrada por los artículos 8 y 25 de la Convención Americana de Derechos Humanos, se relaciona en forma directa con idea que el sujeto afectado pueda recurrir a los tribunales y obtener la satisfacción de su derecho en un "plazo razonable". No hay que dejar de reconocer que esto implica que el legislador tiene la obligación de brindarle a todo juez medios judiciales idóneos para el ejercicio de este nuevo papel. Si no se asegura la efectividad de los derechos por medio de la incorporación de normas de carácter procesal en el derecho de fondo, difícilmente se pueda hacer efectivo el derecho material.

Por otra parte, como es sabido, las normas relativas al proceso no se encuentran ubicadas exclusivamente en los códigos procesales y en las leyes de organización y competencia de los órganos judiciales, sino que también las hay en los Códigos de fondo a los que se refiere el artículo 67, inciso 11, de la Constitución Nacional y en diversas leyes nacionales. Aun cuando, de conformidad al sistema federal adoptado por la Constitución, la atribución de regular los procesos corresponde a las legislaturas provinciales, sus facultades para legislar en materia procesal deben ser entendidas sin perjuicio de las normas de ese carácter que puede dictar el Congreso a los fines de asegurar la efectividad del ejercicio de los derechos que consagra la legislación de fondo.

Por consiguiente, la inclusión de disposiciones procesales en el Código Civil y Comercial no debe entenderse como un avance sobre las autonomías provinciales, pues el poder de las provincias no es absoluto y el Congreso Nacional cuenta con facultades para dictar normas procesales cuando sea pertinente asegurar la eficacia de las instituciones reguladas por los códigos de fondo y evitar el riesgo de desnaturalizar instituciones propias del denominado derecho material. 


\section{A modo de conclusión}

La introducción en el Código Civil y Comercial de un título preliminar nos permite poner en contexto las distintas instituciones que se encuentran reguladas y considerar la perspectiva desde la cual se debe leer, analizar e interpretar las distintas normas. Son los tres primeros artículos los que nos hablan sobre las fuentes del derecho (artículo 1), la interpretación jurídica, del control de constitucionalidad y del control de convencionalidad (artículo 2) y por último el artículo 3 sobre la fundamentación de la decisión jurisdiccional.

Particularmente, el artículo 3 del CCiv. y Com. nos dice que el dictado de la resolución judicial es parte de la función del juez, ya que esto hace a la propia identidad de magistrado, al relacionarse con su función, pero también con finalidad social del derecho, que no es otro que lograr la paz social. Si no fuera así, su existencia sería totalmente contradictoria con el ejercicio de su cargo y el desempeño de su actividad.

Cuando el juez admite una demanda, realiza un pronunciamiento judicial, pero también cuando la rechaza, motivado en la ausencia de una ley que pueda dar sustento a la pretensión de una parte.

Carlos Cossio se ha detenido, en sus diferentes obras, en el análisis de la función judicial, desde el enfoque particular que le imprime la Teoría Egológica, afirmando que el Código impone al juez la necesidad de juzgar desde un sentido apriorístico, fundado en el principio lógico de no contradicción: La necesidad lógica de juzgar que tiene el juez deriva, entonces, de la estructura lógica del deber ser que se encuentra implícita en las normas jurídicas. Cuando nos colocamos en la esfera del derecho, las normas conforman para nuestra conducta, una estructura constitutiva de sentido, que no es fruto de nuestro albedrío, ni del albedrío del legislador, solo pertenecen al ordenamiento jurídico permitiendo de este modo establecer una valoración objetiva de las acciones conforme lo prescripto por el derecho (Cossio, 1947, p. 54).

Asimismo, podemos afirmar que una de las características con la cual debe contar la decisión jurisdiccional tiene que ver con la adecuación a normas jurídicas válidas. No obstante, la otra característica que también se encuentra presente en la sentencia es la existencia de criterios de índole axiológica. En este sentido, Aarnio plantea la necesidad de que la decisión judicial sea aceptable, tanto desde su sentido formal como en su sentido material. En lo formal, implica el reconocimiento de normas válidas y eficaces por parte del juzgador. Pero también, la decisión debe ser axiológicamente válida para que ella sea aceptada en un sentido material, porque hay que tener en cuenta que la aceptabilidad social legitima la decisión tomada. En consecuencia, este criterio de aceptación solo es posible 
alcanzarlo utilizando un discurso racional (Aarnio, 2005, p. 54). Este tipo de discurso obtiene su identidad de aquellos procedimientos de justificación que utiliza y de los fundamentos argumentativos, basado en los principios jurídicos.

Si tomamos en cuenta un punto de vista gnoseológico intersubjetivo, tendremos la necesidad de distinguir entre las normas como texto, de lo que ella expresa como significación (1). Como explica Pettoruti, el proceso de justificación implica necesariamente la referencia a los valores, por ello cabe afirmar que razonabilidad y valoración no se tratan de elementos excluyentes o antitéticos, sino que se interrelacionan en el concepto de "razón práctica". Por eso, afirma que

Los aspectos lógico-formales de las normas son un principio ordenador a priori que dota de coherencia al sistema jurídico, pero los aspectos teleológicos o finalistas actúan en el plano histórico, atribuyendo sentidos valorativos a los contenidos sociales. Es ésa y no otra la explicación por la cual permanentemente se hallan situaciones en las cuales, más allá de la validez formal de una norma, se le atribuyen distintos significados interpretativos, algunos de los cuales pueden hasta a llegar a dejarla sin efecto frente a una situación insostenible de las presiones sociales (Pettoruti, 2007, p. 215).

Esta perspectiva nos lleva a entender que el derecho es visto como un instrumento flexible y capaz de adaptarse a lo que el juez considera como prioritario para la sociedad, ya que su papel es conciliar las leyes y las instituciones establecidas, de manera tal que con ello se ponga de manifiesto no sólo la legalidad, sino también el carácter razonable de sus decisiones.

El proceso de individualización y concreción de las normas jurídicas nos muestra el sentido dinámico del ordenamiento. La aplicación de las normas implica necesariamente el dominio de un método de interpretación y utilización de una lógica de la acción humana, esto es lo que Recacéns Siches llama lógica de lo razonable, en la cual se conjugan distintos elementos: a) las normas jurídicas; b) desde un punto de vista histórico, y c) según un aspecto práctico o de aplicación del orden jurídico vigente, subrayando de este modo la importancia de los principios jurídicos positivizados por el legislador (Recaséns Siches, 1956, p. 324). Los principios no dejan de ser esa llave que nos permiten actualizar la interpretación normativa, sin necesidad de un cambio en la legislación. Es que estos funcionan como criterios interpretativos, no estancos y absolutos, sino dinámicos y variables, en la medida que la textura abierta que ellos poseen nos permite ampliar

(1) Para Dilthey la interpretación es parte del acto gnoseológico de comprender, por lo que solo puedo interpretar en la medida que he comprendido. Proceso que implica partir de la manifestación de los signos sensibles hacia su significación (Ricoeur, 2001, p. 132). 
o modificar la consideración efectiva que podemos realizar, como así también la caracterización que hacemos sobre cada uno de ellos. Labor que, por cierto, la vemos concretizada en la constante labor jurisprudencial desarrollada por los distintos operadores jurídicos.

\section{Bibliografía}

Aarnio, A. (2005). Algunas observaciones sobre la justificación jurídica. Revista La ley. Buenos Aires: La ley.

Alexy, R. (2003). El concepto y la validez del derecho. Barcelona: Gedisa.

Aristóteles (1999). Ética. Madrid: Alba.

Bidart Campos, G. (2000). Tratado Elemental de Derecho Constitucional Argentino. Buenos Aires: Ediar.

Cossio, C. (1947). La plenitud del ordenamiento jurídico, 2a ed. Buenos Aires: Los Andes.

Cueto Rua, J. (1994). Fuentes del Derecho. Buenos Aires: Abeledo Perrot.

Herrera Figueroa, M. (1955). Justicia y sentido. Tucumán: Ministerio de educación de la Nación. Universidad Nacional de Tucumán.

Kant, I. (2007). Hacia la paz perpetua: un proyecto filosófico. Bernal: Universidad Nacional de Quilmes.

Kelsen, H. (2003). La paz por medio del Derecho. Buenos Aires: Trotta.

Kelsen, H. (1991). Teoría Pura del Derecho. México: Porrúa.

Mondolfo, R. (1983). El pensamiento antiguo. Historia de la filosofía greco-romana. Buenos Aires: Losada.

Pettoruti, C. E. (2004). La validez del derecho. Buenos Aires: La ley.

Pettoruti, C. E. (2007). Aportes para una filosofía de la interpretación. Anales de la Academia Nacional de Derecho y Ciencias Sociales de Córdoba. Córdoba: Advocatus.

Recaséns Siches, L. (1956). Nueva filosofía de la interpretación del Derecho. México: Fondo de Cultura Económica. 
Ricour, P. (2001). Del texto a la acción. Buenos Aires: Fondo de cultura económica.

Vigo, R. (2003). Balance de la Teoría Jurídica Discursiva de Robert Alexy. Anuario de la Asociación Argentina de Filosofía del Derecho, No 3. Buenos Aires: Rubinzal-Culzoni.

Fecha de recepción: 02-04-2019

Fecha de aceptación: 13-09-2019 
